UDC 629.111.35

SCOPUS CODE 2210

https://doi.org/10.36073/1512-0996-2020-2-110-116

\title{
Force analysis of stair climber's running gear
}

David Tavkhelidze

Zurab Mchedlishvili
Department of Agro-engineering, Georgian Technical University, 17 D. Guramishvili str, 0192 Tbilisi, Georgia

E-mail: d.tavkhelidze@gtu.ge

Department of Engineering Graphics and Technical Mechanics, Georgian Technical University, 68 ${ }^{\text {a }}$. Kostava str. 0160

E-mail: zurab.mch@mail.ru

\section{Reviewers:}

G. Goletiani, Professor, Faculty of Transportation and Mechanical Engineering, GTU

E-mail: gia_goletiani@yahoo.com

T. Mchedlishvili, Professor, Faculty of Transportation and Mechanical Engineering, GTU

E-mail: t.mchedlishvili@gtu.ge

Abstract. The article refers to the determination of main physical parameters of running gear of invented stair climber platform for different purposes, in particular the mentioned platform is intended to be used for a disabled person. In order to improve stability of the platform a new lever mechanism is offered in the paper, providing smooth transition of the machine from inclined to the plane parts of staircase. The article considers kinematic and force analysis of the proposed mechanical system in order to determine appropriate constructive parameters.

Key words: Kinematics; lever mechanism; stair climber; stiffness of lever mechanism.

\section{Introduction}

To provide a disable person with the facilities to overcome such obstacles as stairs, there has been

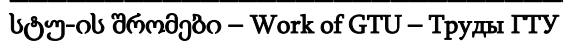

invented stair climber with original scheme of frame at Georgian Technical University. The mentioned machine is depicted on the Fig 1.

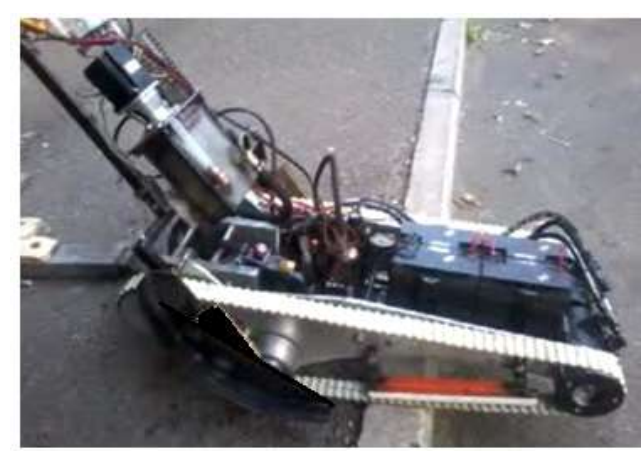

Fig.1 The pilot model of stair climber

As shown in the figure, the mechanical system comprises of the frame and different mechanical systems with actuators and executive mechanisms. However, one of common problems characterising almost each such kind of machine is the moment when machine overcomes the last step of staircase, continuing movement on stair platform. This transition process is 
happening at the moment when the machine is passing its centre of gravity, which is occurring with sadden lending of the device on a flat surface of stair platform. The described process negatively influences on the dynamic stability of the device and safe operation of the machine and also puts obstacles in the way of usage of the device by disable persons independently.

\section{Main part}

\section{The kinematic scheme of the mechanism}

The given mechanical system consists of different types of bars and construction elements with various types of junctions of adjacent links. For the purpose of proper design of multilink mechanical systems, it is necessary to determine stiffness parameters of the bar taking into account movement of the machine on stairs.

Fig. 2 presents the scheme of the movable platform with multi-bar mechanism that would sensitively improve device's movement on stairs, softening described transition movement. Therefore disable persons can use the device without any assistants. The given platform contains the following main parts: 1 . Rubber toothed track; 2. Hydraulic actuator for inclination of holder of backrest of wheel chair; 3,10. Driven wheels; 4. Rocker of right part of lever mechanism; 5. Springs and pusher bar; 6 . Lock of back of wheel chair 7. Side frame that supports all parts of the machine; 8. Rocker of left part of lever mechanism; 9. Mechanism for inclination of holder of backrest of wheel chair 11. Driving wheel; 12. Wheel chair; 13 . Holder of backrest of wheel chair.

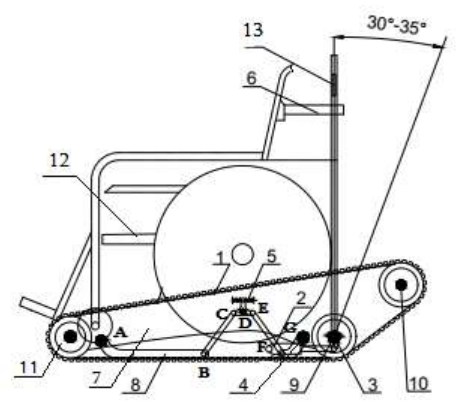

Fig.2 Scheme of the movable platform with multi-bar mechanism

\section{Motion of stair climber}

In order to set up the equation of uniform motion of the device, it is necessary to examine the position of the machine during its motion on stairs. Design diagrams of the said positions of the machine are given on the Fig. 3 .

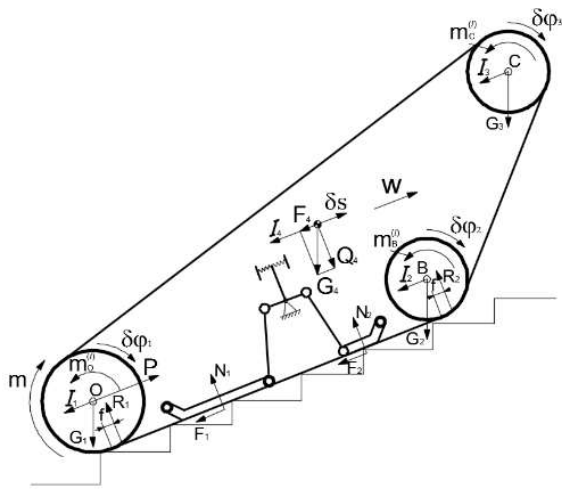

Fig. 3. Design diagram of climber during its motion on stairs.

During the climber movement there are generated different forces, which can be characterized as: $F_{1}$ and $F_{2}$ - slide friction forces acting at the touching place of the track with the edge of the step of the stair; $N_{1}$ and $N_{2}$ forces of reaction acting on the $\mathrm{AB}$ and $\mathrm{GF}$ guides (see Fig .4); $G$ - the force of gravity. Herewith $F$ and $P$ are the constituents of the gravity force; $\mathrm{M}$ is the torque acting on the driving wheel, while $m o, m_{b}$ and $m_{c}$ are the moments of the forces of friction that are acting between wheels and track; $R_{1}$ and $R_{2}$ - reaction forces functioning at the point of touching of driving and driven wheels with stair or floor.

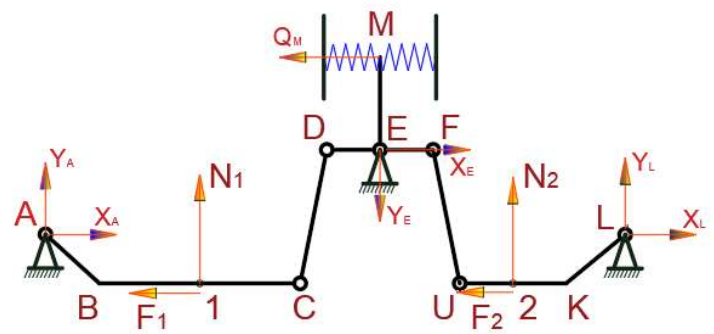

Fig.4. The design diagram of the mechanism for smooth transition of the transporter from last step of stairs to staircase. 
In our case, in order to determine displacements of the given mechanism's links, we will use the method of possible displacements. According to this method, if we give the possible displacement to $\mathrm{ABC}$ linkage then the first point at which is modulated the force $N_{l}$ will get the displacement:

$$
\delta \varphi_{1}=\frac{\delta s_{1}}{r_{1}} ;
$$

At the same time $C$ point has the following possible displacement:

$$
\delta s_{2}=r_{2} \cdot \delta \varphi_{1} .
$$

As we see from mechanism's design diagram, CD linkage makes complex planar displacement, therefore its last points get possible displacements $\delta_{s 2}$ and $\delta_{s 3}$. To find out relations in specified displacements we need to find $C D$ linkage center's $V$ point location.

From $\mathrm{ABC}$ and VCD triangles, we get $\mathrm{BCA}=\mathrm{DVC}$

$\mathrm{C}$ and $\mathrm{D}$ points possible displacement relation is:

$$
\frac{\delta s_{2}}{\delta s_{3}}=\frac{|V C|}{|V D|}=\cos (\widehat{D V C})=\cos \alpha
$$

Where from

$$
\delta s_{3}=\frac{\delta s_{2}}{\cos \alpha}=\frac{r_{2}}{r_{1} \cos \alpha} \cdot \delta s_{1}
$$

Based on design diagram, it is seen that $\mathrm{E}$ point, which is located on DF link, is fixed EM axis perpendicular to the mentioned link and is connected with springs (see Fig. 4) that is necessary for achieving equilibrium position of linkage. By the denoting the possible displacement $\delta S_{m}$ of the M point, it can be determined from the following equalities:

$$
\begin{gathered}
\frac{\delta s_{3}}{r_{3}}=\frac{\delta s_{M}}{r_{M}} \\
\delta s_{M}=\frac{r_{M}}{r_{3}} \cdot \delta s_{3}=\frac{r_{M} \cdot r_{2}}{r_{3} \cdot r_{1} \cdot \cos \alpha} \cdot \delta s_{1}
\end{gathered}
$$

As seen from the Fig.4, the sections $|\mathrm{DE}|=|\mathrm{EF}|$ of the link DF. Terefore spring's possible displacement and $\mathrm{F}$ point's possible displacement are the correlations. This relation can be expressed by the following ratios:

$$
\frac{\delta s_{3}}{r_{3}}=\frac{\delta s_{4}}{r_{4}},
$$

from where we will obtain:

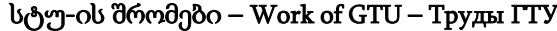

$$
\delta s_{4}=\frac{r_{4}}{r_{3}} \cdot \delta s_{3}=\frac{r_{4} \cdot r_{2}}{r_{3} \cdot r_{1} \cdot \cos \alpha} \cdot \delta s_{1}
$$

At the same time UF-link makes planar motion and that is why for determination of $\delta s_{5}-$ possible displacement we need to find by its instant center's Z location. In comparison with UKL and UZF triangles, we get LKUL $=$ LUFZ and it is possible to write down

$$
\frac{\delta s_{4}}{\delta s_{5}}=\frac{|F Z|}{|U Z|}=\frac{1}{\cos \beta}
$$

In case we take into account correlation between $\mathrm{F}$ and $\mathrm{U}$ points, then it will be possible to obtain possible displacement $\delta s_{5}$, which can be determined as:

$$
\delta s_{5}=\delta s_{4} \cdot \cos \beta=\frac{r_{4} \cdot r_{2} \cdot \cos \beta}{r_{3} \cdot r_{1} \cdot \cos \alpha} \cdot \delta s_{1}
$$

And hence $2^{\text {nd }}$ point's possible displacement can be obtained as following ratio:

$$
\frac{\delta s_{5}}{r_{5}}=\frac{\delta s_{6}}{r_{6}}
$$

On the basis of this ratio, it can be calculated $\delta s_{6}$ by the following formula:

$$
\delta s_{6}=\frac{r_{6}}{r_{5}} \cdot \delta s_{5}=\frac{r_{6} \cdot r_{4} \cdot r_{2} \cdot \cos \beta}{r_{5} \cdot r_{3} \cdot r_{1} \cdot \cos \alpha} \cdot \delta s_{1}
$$

At the same time the key point of the linkage is displacement of point $\mathrm{M}$, which predestinates smooth movement of the machine in case of its displacement from stairs to entryway and hence constructive parameters of linkage. In order to find $M$ point's full displacement, it is necessary to use possible displacement principles for the determination of works done by forces of reactions rising during the motion. The system of equations that determines displacement of point $\mathrm{M}$, can be written as:

$$
\begin{gathered}
N_{1} \cdot \delta s_{1}-N_{2} \cdot \delta s_{6}-c \cdot h \cdot \delta s_{M}=0 \\
c \cdot h \cdot \delta s_{M}=N_{1} \cdot \delta s_{1}-N_{2} \cdot \delta s_{6}
\end{gathered}
$$

After setting the above relations in these equations, we obtain:

$$
\begin{gathered}
c \cdot h \cdot \frac{r_{M} \cdot r_{2}}{r_{3} \cdot r_{1} \cdot \cos \alpha} \cdot \delta s_{1}= \\
=N_{1} \cdot \delta s_{1}-N_{2} \cdot \frac{r_{6} \cdot r_{4} \cdot r_{2} \cdot \cos \beta}{r_{5} \cdot r_{3} \cdot r_{1} \cdot \cos \alpha} \cdot \delta s_{1} \\
c \cdot h=N_{1} \cdot \frac{r_{3} \cdot r_{1} \cdot \cos \alpha}{r_{M} \cdot r_{2}}-N_{2} \cdot \frac{r_{6} \cdot r_{4} \cdot \cos \beta}{r_{M} \cdot r_{5}}
\end{gathered}
$$


Based on the given equations, it's easy to calculate amount of squeezing or stretching of the springs by equation (16)

$$
h=N_{1} \cdot \frac{r_{3} \cdot r_{1} \cdot \cos \alpha}{c \cdot r_{M} \cdot r_{2}}-N_{2} \cdot \frac{r_{6} \cdot r_{4} \cdot \cos \beta}{c \cdot r_{M} \cdot r_{5}}
$$

In order to determine the structural parameters of the mechanism it is necessary to define values of reaction forces acting on A, E and L kinematic pairs, which are fixed on the frame of the machine. The forces of reactions are risen in these points, with unknown directions of acting and the volumes of these forces. In order to define such forces, it is the most convenience to operate with their components distributed on the axes of planar Cartesian systems fixed on the mentioned points of the frame. It means that we will operate with the following forces:

$$
\left(X_{A}, Y_{A}\right),\left(X_{E}, Y_{E}\right),\left(X_{L}, Y_{L}\right)
$$

For the determination of these reactions let's use possible displacement principle, for what, initially it is necessary to formulate the system of equations of works fulfilled by the forces of reactions acting on the $A B C$ link. Let's write equation of works done during the possible displacement of point $\mathrm{A}$ along the $\mathrm{X}$ axis.

$$
-F_{1} \cdot \delta s_{A X}+X_{A} \cdot \delta s_{A X}=0
$$

Here it is necessary to determine:

$$
F_{1}=X_{A}
$$

In order to find out $Y_{A}$ reaction force, let's give vertical possible displacement to A point and write the following equation:

$$
N_{1} \cdot \delta s_{1}+Y_{A} \cdot \delta s_{A Y}=0
$$

Taking into account the following ratios:

$$
\frac{\delta s_{1}}{|C 1|}=\frac{\delta s_{A Y}}{|C A|} ; \delta s_{A Y}=\frac{\delta s_{1}}{|C 1|} \cdot|C A|,
$$

The (19) can be written as:

$$
N_{1} \cdot \delta s_{1}+Y_{A} \cdot \frac{|C A|}{|C 1|} \delta s_{1}=0
$$

From where it is obtained:

$$
Y_{A}=-N_{1} \cdot \frac{|C 1|}{|C A|}
$$

The (21) shows that $Y_{A}$ force is acting in opposite direction.
Let's formulate the analogue equations for UKL link. That's why we need to give possible displacement to $\mathrm{L}$ point relatively to $X$ axis:

$$
-F_{2} \cdot \delta s_{6 X}+X_{L} \cdot \delta s_{L X}=0
$$

where: $\delta s_{6 X}=\delta s_{L X}$

Taking into consideration the last equality, it can be written that:

$$
X_{L}=F_{2}
$$

In order to find out $Y_{L}$ reaction, it is necessary to give the vertical possible displacement to $\mathrm{L}$ point and formulate the following equation:

$$
N_{2} \cdot \delta s_{6}+Y_{L} \cdot \delta s_{L Y}=0
$$

Here: $\quad \frac{\delta s_{6}}{|U 2|}=\frac{\delta s_{L Y}}{|U L|} \delta s_{L Y}=\frac{\delta s_{6}}{|U 2|} \cdot|U L|$

From which we will get:

$$
Y_{L}=-N_{2} \cdot \frac{|U 2|}{|U L|}
$$

consequently $Y_{L}$ force reaction gets opposite direction.

Eventually let's determine force of reactions operating in the point $\mathrm{E}$, by which we give this point possible displacement to the direction consistently to $\mathrm{X}$ and $\mathrm{Y}$ axis. From the beginning we write:

$$
N_{1} \cdot \delta s_{1}+N_{2} \cdot \delta s_{6}-Y_{E} \cdot \delta s_{E Y}=0
$$

To solve this equation it is necessary to express $\delta s_{6}$ and $\delta s_{E Y}$ possible displacements by $\delta s_{1}$ that allows to write down the following equation

$$
\begin{gathered}
N_{1} \cdot \delta s_{1}+N_{2} \cdot \frac{r_{6} \cdot r_{2} \cdot \cos \beta}{r_{5} \cdot r_{1} \cdot \cos \alpha} \cdot \delta s_{1}- \\
-Y_{E} \cdot \frac{r_{2}}{r_{1} \cdot \cos \alpha} \cdot \delta s_{1}=0
\end{gathered}
$$

From here we will obtain:

$$
Y_{E}=N_{1} \cdot \frac{r_{1} \cdot \cos \alpha}{r_{2}}+N_{2} \cdot \frac{r_{6} \cdot \cos \beta}{r_{5}}
$$

As it can be seen from Fig.4, there are no forces from other link to the DEFM link except spring's force acting along $\mathrm{X}$ axis, that is why reaction force that is operating in E kinematic pair equals to spring's reaction force with minus sign:

$$
X_{E}=-c \cdot h=-N_{1} \cdot \frac{r_{3} \cdot r_{1} \cdot \cos \alpha}{r_{M} \cdot r_{2}}+N_{2} \cdot \frac{r_{6} \cdot r_{4} \cdot \cos \beta}{r_{M} \cdot r_{5}}
$$


So, all the reaction forces acting on the frame of the mechanism are determined and as a result all constructive parameters of the given mechanism can be defined.

\section{Conclusion}

As it was mentioned, the mechanism considered here can be used not only for machines assigned for transportation of handicap people, but also for any other machines with track drives.
Given calculation method allows to define constructive parameters of mentioned mechanism. The design diagram of mechanism is statically nondetermined and hence for the definition of necessary force factors acting on the mechanism and accordingly for the determination of mechanism's constructive characteristics it has been used the method of possible dissplacement, which gave good results and because of simplicity of obtained expresions this method can be used for the calculations of similar mechanical systems.

\section{References}

1. Targ S. M. A short course of theoretical mechanics: A textbook. 18th ed. M.: "Higher School". 2010. (in Russian).

2. Zienkevich O.C. The finite element method in engineering science. Mcgraw-Hill-London. 1971.

3. Markeev A.P. Theoretical mechanics. Izhevsk: "Regular and chaotic dynamics". 2001, 592 p. (in Russian).

4. Tavkhelidze D., Mchedlishvili Z. Geometry of five link mechanisms with two degrees of freedom. Journal of mathematical sciences. Vol. 195. Issue 4. Springer. 2013, 560-568 pp. 


\section{UDC 629.111.35}

SCOPUS CODE 2210

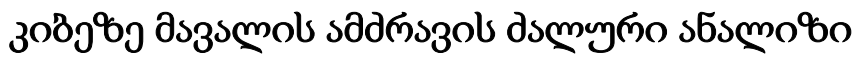

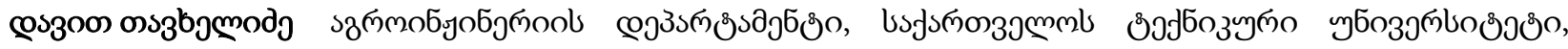

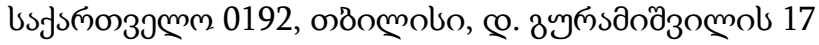

E-mail: d.tavkhelidze@gtu.ge

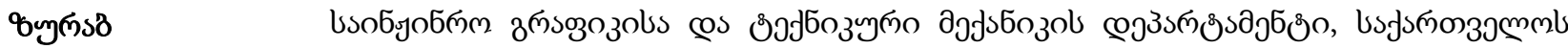

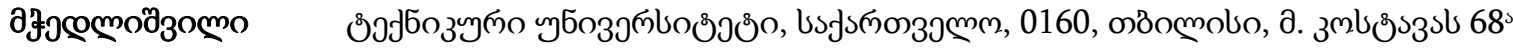

E-mail: zurab.mch@mail.ru

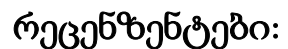

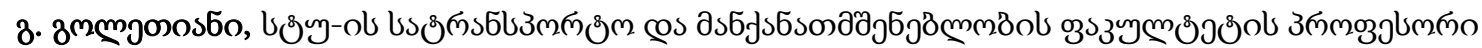

E-mail: gia_goletiani@yahoo.com

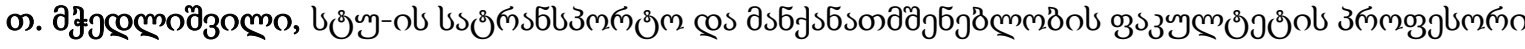

E-mail: T.mchedlishvili@gtu.ge

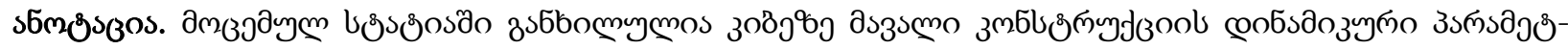

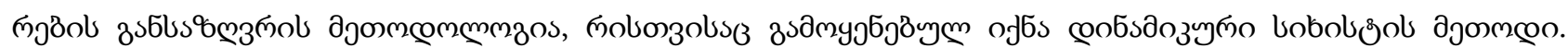

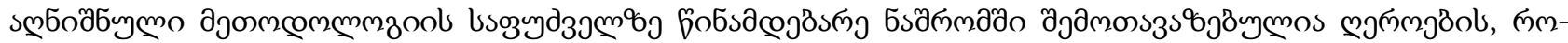

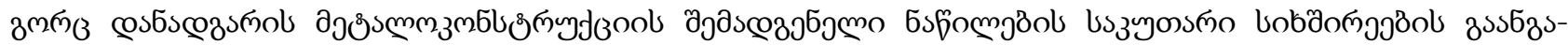

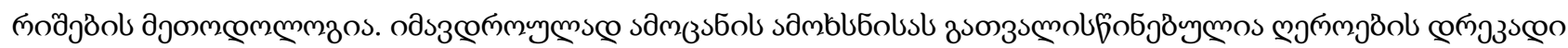

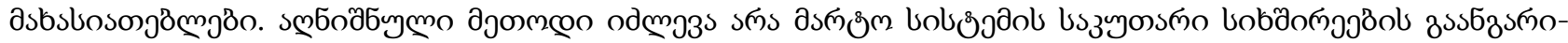

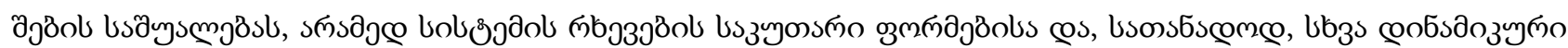

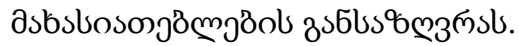

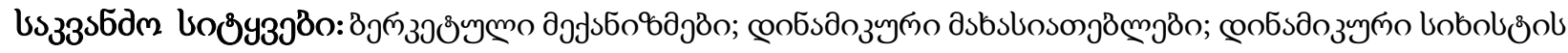

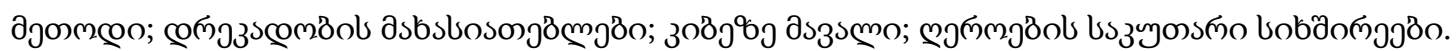




\section{UDC 629.111.35}

SCOPUS CODE 2210

\section{Силовой анализ ходовой части лестничного подъемника}

Давид Тавхелидзе Департамент Агроижинерии, Грузинский технический университет, Грузия, 0192, Тбилиси, ул. Д. Гурамишвили 17

E-mail: d.tavkhelidze@gtu.ge

Зураб Мчедлишвили Департамент, инженерной графики и технической механики Грузинский технический университет, Грузия, 0160, Тбилиси, ул. Костава $68^{\text {a }}$

E-mail: zurab.mch@mail.ru

\section{Рецензенты:}

Г. Голетиани, профессор факультета транспорта и машиностроения ГТУ

E-mail: gia_goletiani@yahoo.com

3. Мчедлишвили, профессор факультета транспорта и машиностроения ГТУ

E-mail: T.mchedlishvili@gtu.ge

Аннотация. Данная статья посвящена расчету основных конструктивных параметров ходовой части самоходной платформы для подъема по лестнице для различных целей, в частности упомянутая платформа предназначена для использования инвалидами. В целях повышения устойчивости платформы в данной работе предлагается новый рычажный механизм, обеспечивающий плавный переход машины от наклонной части лестницы на плоской части лестничной клетки. В порядке определения конструктивных параметров в статье приводятся кинематический и силовой анализ предлагаемой механической системы.

Ключевые слова: лестничная самоходная платформа; рычажный механизм; кинематика; жесткость рычажного механизма.

The date of review 18.12.2019

The date of submission 23.12.2019

Signed for publishing 08.07.2020 